\title{
The Feedback Session of an Autism Assessment: A Scoping Review of Clinical Practice Guideline Recommendations
}

\author{
Ellen Pattison ${ }^{1}$ (1) $\cdot$ Alexandra Ure ${ }^{2,3,4,5} \cdot$ Sharon R. Mittiga ${ }^{1} \cdot$ Katrina Williams $^{2,3,4,6} \cdot$ Nerelie C. Freeman $^{1}$
}

Accepted: 3 May 2021 / Published online: 25 May 2021

(c) The Author(s), under exclusive licence to Springer Science+Business Media, LLC, part of Springer Nature 2021

\begin{abstract}
This review aimed to assess the quality and content of recommendations for delivering an autism diagnosis, published internationally within clinical practice guidelines. Seventeen relevant guidelines were identified. When methodological information was provided, recommendations for feedback were predominantly formed through consensus. Recommendations consistently included who should attend feedback, the timing and mode of delivery, the clinician's manner, and what should be discussed and/or included in an accompanying report. Specific recommendations were not consistent however, and a number of gaps were identified, such as the inclusion of educators and educational specific recommendations. Although individual variation is necessary for autism diagnosis disclosure, agreement on minimum standards of practice is warranted. Further investigation is required to establish best practice.
\end{abstract}

Keywords Autism $\cdot$ Assessment $\cdot$ Feedback $\cdot$ Guidelines $\cdot$ Diagnosis disclosure

\section{Introduction}

The American Psychiatric Association (2013) defines autism spectrum disorder (autism) as a neurodevelopmental disorder associated with persistent difficulties in social interactions and communication, as well as rigid and repetitive patterns of thinking and behaviour. Behavioural characteristics of autism can vary in nature and severity between individuals and within the same individual across their lifespan (American Psychiatric Association [APA], 2013; Williams

Ellen Pattison

ellen.pattison@monash.edu

1 Faculty of Education, Monash University, Clayton, VIC, Australia

2 Department of Paediatrics and Education Research, Monash University, Clayton, VIC, Australia

3 Department of Developmental Paediatrics, Monash Children's Hospital, Clayton, VIC, Australia

4 Department of Neurodisability and Rehabilitation Research, Murdoch Children's Research Institute, Melbourne, VIC, Australia

5 Department of Mental Health, Royal Children's Hospital, Melbourne, VIC, Australia

6 Department of Paediatrics, University of Melbourne, Melbourne, VIC, Australia et al., 2014). Intellectual and language abilities also differ between individuals (APA, 2013; Klopper, 2017; World Health Organisation [WHO], 2018) and attention, behaviour and mood difficulties frequently co-occur (Klopper, 2017; Simonoff et al., 2008). This range of features can impact the presentation of autism in an individual, adding complexity to assessment and diagnosis. In the absence of biological indicators, autism is defined and diagnosed based on reported and observed behaviours and relies on the clinical judgement of experienced clinicians (Rogers et al., 2016; Ward et al., 2016).

Clinical guidance documents play an important role in shaping best practice parameters for autism diagnostic assessments. Numerous autism assessment guidelines have been published by government jurisdictions and professional associations (Penner et al., 2018). However, recent reviews of the quality and content of these guidelines revealed inconsistencies pertaining to all aspects of the autism diagnostic assessment, including whether autism must be diagnosed by a multidisciplinary team (MDT), the composition of the MDT and the time frame for completion of the assessment (Hayes et al., 2018; Penner et al., 2018). Variations and ambiguity also exist around other recommendations relating to the key elements of the assessment, including the choice of diagnostic tools and the classification system to utilise. Appraisals also identified variability in the identification 
and synthesis of empirical evidence supporting the recommended diagnostic practices and little guidance in relation to their applicability to health services associated with autism (Hayes et al., 2018; Penner et al., 2018). Notably, reviews to date have not focused on the recommendations for the feedback of diagnostic assessment results to families and/or the individual themselves.

The feedback session acts as an interface between the assessment process and a period of understanding, support and intervention for families. The value of a meaningful feedback is highlighted in reports of parents' experiences. The first communication of a child's developmental disability diagnosis can be an enduring memory for parents (Hasnat \& Graves, 2000) and, all too often, a distressing and overwhelming experience (Hennel, 2016; Mulligan et al., 2012). Parents have reported being able to distinguish between their personal reactions to the diagnosis itself, and their reactions to how the diagnosis was delivered (Fallowfield \& Jenkins, 2004). Only half of the families surveyed expressed satisfaction with the way their child's autism diagnosis was disclosed (Brogan \& Knussen, 2003; Crane et al., 2016). Families have described issues relating to the structure, style and content of their autism assessment feedback session (Abbott et al., 2013). Crane et al. (2016) indicated the information provided at feedback and the clinician's manner can influence parents' overall satisfaction with the entire diagnostic process. Potter (2017) reported fathers described frustration related to the "insufficient information" (p. 95) provided to them at feedback, as well as the lack of support offered to them afterwards.

An Australian study highlighted inconsistencies between the information parents perceived to be important to receive at feedback, what they reported receiving and what paediatricians reported providing (Hennel et al., 2016). The majority of parents reported not receiving information about school support or ways of explaining the diagnosis to the child and only $33 \%$ of parents reported discussing a tailored therapy plan with the diagnosing paediatrician. Parents appreciated clinicians being supportive, understanding and hopeful as well as honest, direct and accepting of family concerns during autism assessments and feedback (Abbott et al., 2013; Brogan \& Knussen, 2003; Mulligan et al., 2012; Potter, 2017). Higher satisfaction with feedback was reported when families were given the opportunity to review the assessment, ask questions and leave with written information including reports, fact sheets or other resources about autism (Abbott et al., 2013; Brogan \& Knussen, 2003; Hennel et al., 2016). Parents highly valued clinicians providing multiple appointments for feedback and offering follow up sessions (Carlsson et al., 2016; Mulligan et al., 2012).

Clinicians have emphasised the importance of delivering autism diagnoses from a strength perspective, providing honest but not overwhelming information, using plain language, checking for understanding throughout the session, and answering parent questions (Crane et al., 2018; Nissenbaum et al., 2002; Rogers et al., 2016). Clinicians reported they can find it difficult to balance conversations with positive and accurate information, manage parents' distress and expectations, and provide adequate support and referral recommendations following the diagnosis (Crane et al., 2018; Nissenbaum et al., 2002; Rogers et al., 2016).

To date, no review has focused specifically on recommendations for autism assessment feedback within clinical practice guidelines. The aim of this study was to review currently available autism assessment clinical practice guidelines to compare and contrast recommendations for feedback. A critical appraisal of these specific recommendations is essential as these documents are used to inform practice. Lack of clarity or detail can result in a lack of focus on this important component of the assessment process. The objectives of this review were to (1) assess the quality of recommendations for feedback within autism assessment clinical practice guidelines, (2) establish what is currently considered best practice for autism diagnostic assessment feedback, and (3) identify gaps or inconsistencies in recommendations that may require further investigation.

\section{Method}

Given the purpose of our review is to identify and map available evidence, a scoping review methodology was considered most appropriate as per the guidelines outlined by Munn et al. (2018). The Joanna Briggs Institute (JBI) methodology and Preferred Reporting Items for Systematic Reviews extension for Scoping Reviews (PRISMA-ScR) protocol were followed (Peters et al., 2020; Tricco, 2018). A priori protocol was developed before the review was undertaken (available on request).

\section{Literature Search}

The JBI three step search strategy was employed for this review (Peters et al., 2020).

Step one: In March 2020 an initial limited search for autism assessment guidelines in two databases (PubMed and Global Health) was conducted. The titles, abstracts, tables of contents and index words were analysed to construct search terms and the assistance of a research librarian was sought to expand and refine these terms.

Step two: In April 2020 comprehensive and systematic searches were conducted of multiple academic and guideline databases including Pubmed, BMJ Best Practice, Guidelines International Network and Guideline Central, as well as government websites of all European countries and North American states. We used various combinations of the 
constructed search terms 'autis*, asd, asc, Asperger*, pervasive develop*, pdd' with 'assessment, diagnosis, diagnostic, feedback, disclosure, evaluation' and 'guide*, parameter, standard, manual, protocol, policy'.

Step Three: The reference lists of guidelines included at the full text review were examined to identify any guidelines not yet included. See Online Resource 1 for the full details of the search strategy.

\section{Guideline Selection}

Duplicate documents were removed. Inclusion and exclusion criteria for guidelines are presented in Table 1. The first author screened all documents by title, abstract and/or table of contents. The first and third authors conducted full text reviews of the remaining documents, using the online platform Covidence (Veritas Health Innovation, 2015). Any disagreements were resolved by a panel of clinician researchers with relevant clinical and research expertise (the second, fourth and fifth authors), who reached verbal consensus about the inclusion of such documents.

\section{Quality Appraisal}

The quality of each guideline was assessed by two authors using the Appraisal of Guideline Research and Evaluation Second Edition (AGREE-II) tool (Brouwers, 2010) as recommended by Siering et al. (2013). Authors used the guideline document and any available supplementary documents for their assessments. No information regarding the Psychological Society of Ireland guideline development process was available.

The AGREE-II tool consists of 23 items organised into six domains: scope and purpose (items 1-3), stakeholder involvement (items 4-6), rigor of development (items 7-14), clarity of presentation (items 15-17), applicability (items 18-21), and editorial independence (items 22-23), followed by two global rating items. Each item asks appraisers to rate how strongly they agree with a statement (for example, item one: "the overall objective(s) of the guideline is (are) specifically described") on a seven-point Likert scale, from strongly disagree to strongly agree. When a difference greater than two points between author's scores for an individual item occurred, both authors were given the opportunity to view the other's comments about score justification and adjust their score. IBM SPSS Statistics version 26 was used to calculate the intra-class correlation coefficients to assess the level of agreement between authors.

As this was a review of assessment guidelines (not management), all AGREE-II items were considered in the context of assessment only. Interpretations of the AGREE-II items relating to management of a disorder were agreed upon before the commencement of appraisals. For example, authors agreed to rate item 16 ("the different options for management of the condition or health issue were clearly presented") based on the way guidelines directed clinicians to information about management and whether recommendations regarding sharing this information with families at feedback were included. Any recommendations relating to the screening and/or management of autism included within some guidelines were not considered during this review.

Domain scores were calculated by summing individual item scores allocated by both reviewers within each domain, and then scaling the total as a percentage of the maximum possible score (Brouwers et al., 2010). Finally, guidelines were categorised as "strongly recommend", "recommend with alterations" or "do not recommend" according to domain percentage scores, similar to other published appraisals of clinical practice guidelines (Amer, 2019; Bennett et al., 2018; Sekercioglu, 2017; Yan et al., 2013).

\section{Data Extraction and Content Analysis}

Data extraction tables were established a priori and updated throughout the data extraction process (Peters et al., 2020). Descriptive summaries of the guidelines were recorded. In
Table 1 Inclusion and exclusion criteria

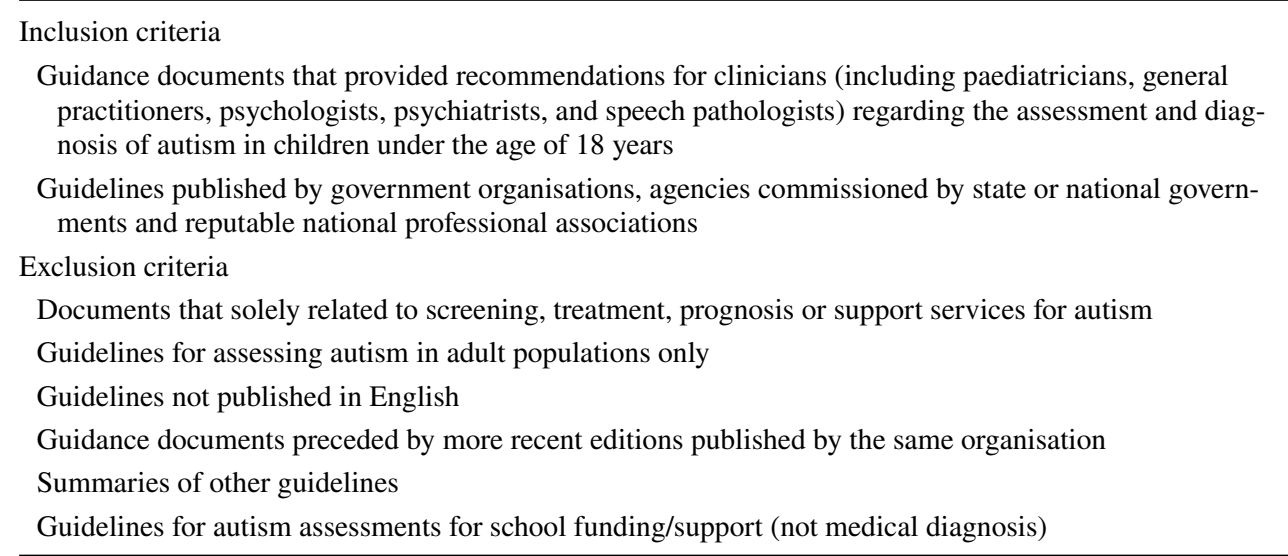


addition, qualitative content analysis was conducted regarding recommendations provided for the assessment feedback session. Specifically, content related to two major themes were extracted: how a feedback session should be conducted and what information should be provided. Recommendations were analysed to identify similarities and inconsistencies between guidelines, gaps within guidelines, and areas that require further consideration and guidance (Levac et al., 2010).

\section{Results}

A total of 955 documents were retrieved from the comprehensive searches and 878 remained after duplicates were removed. Sixty-six guidelines were eligible for full text analysis. Inclusion/exclusion differences occurred for three guidelines, which were all resolved by the reviewing panel of clinician researchers. After consensus was reached, fourteen guidelines met inclusion criteria. A further three guidelines were included after reviewing the reference lists of the 14 included guidelines. A PRISMA diagram presents the selection process (Fig. 1). Details of the included 17 guidelines are presented in Table 2. Of the 17 guidelines included in the study, five (Academy of Medicine Singapore, 2010; Barthélémy et al., 2019; Filipek et al., 2000; Johnson \& Myers, 2007; Volkmar et al., 2014) did not include recommendations for the disclosure of diagnosis or feedback session with the family or child themselves.

\section{Quality Assessment}

There was strong agreement between appraisers (ICC $=0.927, p<0.001$ ) for AGREE II ratings. Scaled domain scores and recommendations for each guideline are presented in Table 3. Based on the scaled domain scores of the overall guideline, six of the autism assessment guidelines were strongly recommended. Eight of the guidelines were recommended with alterations and three were not recommended for use.

\section{Levels of Evidence}

Table 4 presents details of the feedback chapters/sections of the twelve guidelines included for content analysis. Although the HAS (2018) guideline provided a grading system for the evidence quality of recommendations at the beginning of the document, it did not provide grade classifications for the recommendations for feedback. As seen in Table 4, different grades were used to describe the evidence quality supporting recommendations in various guidelines. In practice, however, there were few differences between the quality of evidence utilised across all guidelines that provided information about their development. The five guidelines that described development methods conducted small reviews of limited literature, often including reviewing existing guidelines and community consultation reports. All reported recommendations were based on the consensus opinion of the guideline development group. The CRC (2018) guideline reported utilising a method of reaching consensus amongst experts outside the development group. The NZ (2016), NICE (2017) and SIGN (2016) guidelines reported the guideline development group reached consensus though discussion, but did not report a formal process.

\section{Content Analysis}

\section{Recommendations Regarding How to Conduct Feedback}

There were consistencies as well as gaps across recommendations regarding how to conduct feedback as described further in Table 5.

\section{Consistent Recommendations}

\section{Who Should be Present at Feedback?}

Nine guidelines made recommendations that caregivers be present at feedback. Three of these recommended both parents attend feedback where possible (PSI, 2010; CPS, 2019; HAS, 2018).

\section{Timing of Feedback}

Six guidelines recommended feedback should occur without delay, shortly after the diagnostic evaluation (NICE, 2017; CPS, 2019; UC, 2013; MDMH, 2010; NAS, 2003; CDDS, 2002). Eight guidelines also recommended organising a follow up session between the clinician/s and the family after feedback (NICE, 2017; SIGN, 2016; NY, 2016; HAS, 2018; UC, 2013; MDMH, 2010; NAS, 2003; PSI, 2010).

\section{Manner of the Clinician}

Recommendations from eleven guidelines included: clinicians be honest and accurate, use clear straightforward language and correct terminology, and information be understandable and accessible to a layperson (PSI, 2010; HAS, 2018; NY, 2017; SIGN, 2016; MDMH, 2010; UC, 2013; $\mathrm{CRC}, 2018)$. Clinicians were advised to be compassionate, supportive, understanding, respectful and non-judgemental and to use recognised good practice for disclosing a diagnosis (NICE, 2017; CRC, 2018; HAS, 2018; NZ, 2016; UC, 2013; CPS, 2019; CDDS, 2002; MDMH, 2010). Nine 


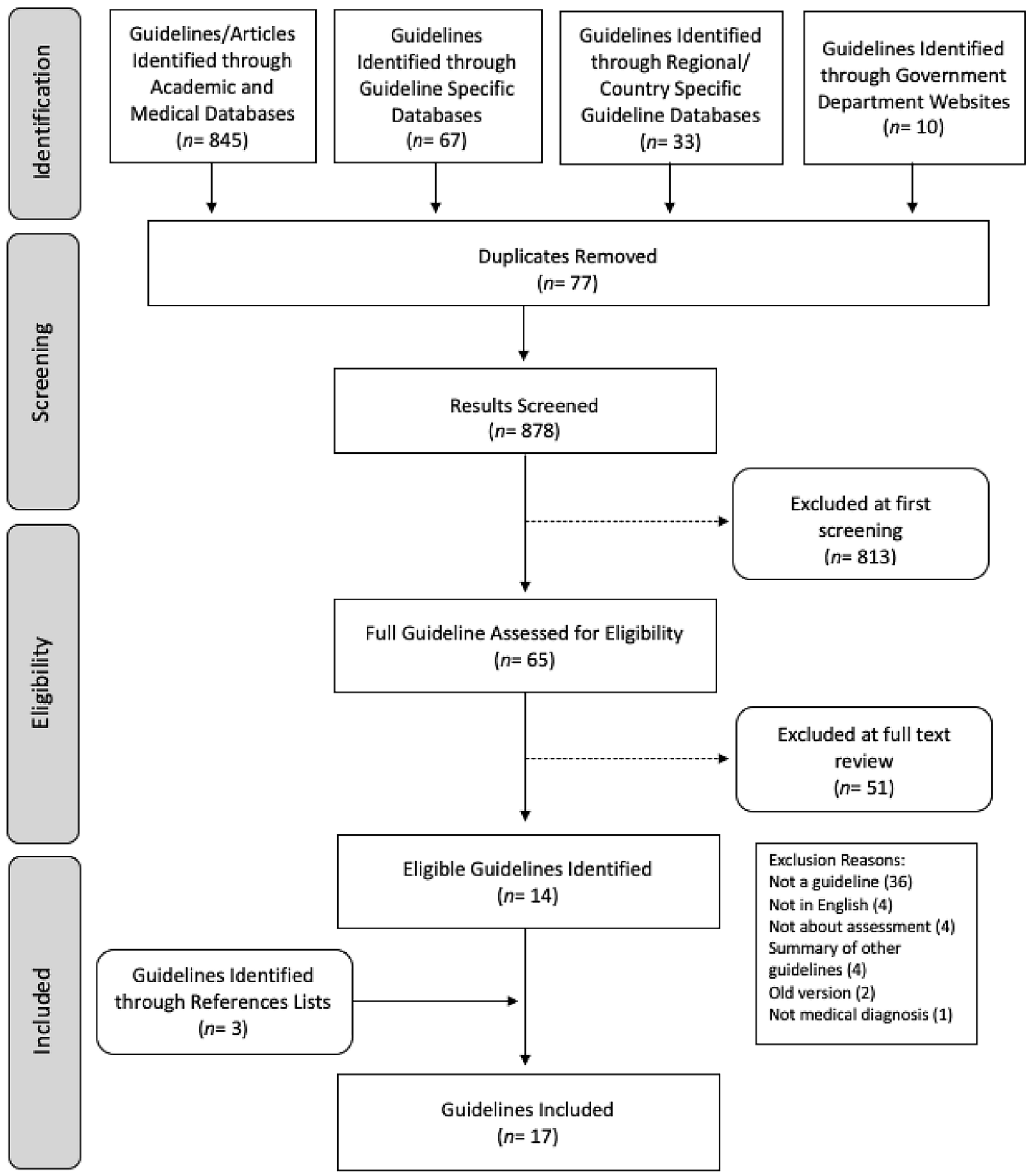

Fig. 1 Guideline selection process

guidelines recommended encouraging/providing opportunity for caregivers to ask questions at feedback (CRC, 2018; SIGN, 2016; NZ, 2016; NY, 2017; HAS, 2018; CPS, 2019; UC, 2013; CDDS, 2002; PSI, 2010).

\section{The Written Report}

Half of the guidelines suggested copies of the report should be provided to the family and others, including the referring clinician (CPS, 2019; NAS, 2003; MDMH, 2010; CRC, 
Table 2 Guidelines included for content analysis

\begin{tabular}{|c|c|c|}
\hline Title & Year & Publisher \\
\hline $\begin{array}{l}\text { People with Autism Spectrum Disorder: Identification, Understand- } \\
\text { ing, Intervention }\end{array}$ & 2019 & Autism Europe (AE; Barthélémy et al., 2019) \\
\hline Standards of Diagnostic Assessment for Autism Spectrum Disorder & 2019 & $\begin{array}{l}\text { Canadian Paediatric Society (CPS; Brian, Zwaigenbaum \& Ip, } \\
\text { 2019) }\end{array}$ \\
\hline $\begin{array}{l}\text { A National Guideline for the Assessment and Diagnosis of Autism } \\
\text { Spectrum Disorders in Australia }\end{array}$ & 2018 & $\begin{array}{l}\text { Cooperative Research Centre for Living with Autism (CRC; White- } \\
\text { house et al., 2018) }\end{array}$ \\
\hline $\begin{array}{l}\text { Autism Spectrum Disorder-Warning signs, Detection, Diagnosis } \\
\text { and Assessment in Children and adolescents }\end{array}$ & 2018 & Haute Autoritè De Santè (HAS; 2018) \\
\hline $\begin{array}{l}\text { Autism Spectrum Disorder under } 19 \mathrm{~s} \text { : Recognition, referral and } \\
\text { diagnosis }\end{array}$ & 2017 & National Institute for Health and Care Excellence (NICE; 2017) \\
\hline $\begin{array}{l}\text { Clinical Practice Guideline on Assessment and Intervention } \\
\text { Services for Young Children (Age 0-3) with Autism Spectrum } \\
\text { Disorder }\end{array}$ & 2017 & $\begin{array}{l}\text { New York State Department of Health and Bureau of Early Inter- } \\
\text { vention (NY; 2017) }\end{array}$ \\
\hline New Zealand Autism Spectrum Disorder Guideline & 2016 & Ministries of Health and Education (2016), New Zealand (NZ) \\
\hline $\begin{array}{l}\text { Assessment, Diagnosis, and Interventions for Autism Spectrum } \\
\text { Disorders }\end{array}$ & 2016 & Scottish Intercollegiate Guidelines Network (SIGN; 2016) \\
\hline $\begin{array}{l}\text { Practice Parameter for the Assessment and Treatment of Children } \\
\text { and Adolescents with Autism Spectrum Disorder }\end{array}$ & 2014 & $\begin{array}{l}\text { American Academy of Child and Adolescent Psychiatry (AACAP; } \\
\text { Volkmar et al., 2014) }\end{array}$ \\
\hline $\begin{array}{l}\text { Connecticut Guidelines for a Clinical Diagnosis of Autism Spec- } \\
\text { trum Disorder }\end{array}$ & 2013 & $\begin{array}{l}\text { University of Connecticut School of Medicine and Dentistry (UC; } \\
\text { 2013) }\end{array}$ \\
\hline $\begin{array}{l}\text { Autism Spectrum Disorders in Pre-School Children: AMD-MOH } \\
\text { Clinical Practice Guidelines }\end{array}$ & 2010 & Academy of Medicine Singapore (AMS-MOH; 2010) \\
\hline $\begin{array}{l}\text { Best Practice Guidelines for the Assessment and Diagnosis of } \\
\text { Autistic Spectrum Disorders for Children and Adolescents (birth } \\
\text { to } 18 \text { years) }\end{array}$ & 2010 & $\begin{array}{l}\text { The Psychological Society of Ireland (Autism Spectrum Disorders } \\
\text { Special Interest Group [PSI], 2010) }\end{array}$ \\
\hline $\begin{array}{l}\text { Autism Spectrum Disorders: Missouri Best Practice Guidelines for } \\
\text { Screening, Diagnosis, and Assessment }\end{array}$ & 2010 & $\begin{array}{l}\text { Thompson Foundation for Autism and the Division of Developmen- } \\
\text { tal Disabilities, Missouri Department of Mental Health (MDMH; } \\
\text { 2010) }\end{array}$ \\
\hline $\begin{array}{l}\text { Identification and Evaluation of Children with Autism Spectrum } \\
\text { Disorders }\end{array}$ & 2007 & American Academy of Pediatrics (AAP; Johnson \& Myers, 2007) \\
\hline National Autism Plan for Children & 2003 & $\begin{array}{l}\text { The National Autistic Society for National Initiative for Autism: } \\
\text { Screening and Assessment (NAS; 2003) }\end{array}$ \\
\hline $\begin{array}{l}\text { Autism Spectrum Disorders: Best Practice for Screening, Diagnosis } \\
\text { and Assessment }\end{array}$ & 2002 & California Department of Developmental Services (CDDS; 2002) \\
\hline Practice Parameter: Screening and Diagnosis of Autism & 2000 & American Academy of Neurology (AAN; Filipek et al., 2000) \\
\hline
\end{tabular}

A more detailed version of this table can be found in Online Resource 2

2018), the child's general practitioner or paediatrician (NAS, 2003; NICE, 2017; UC, 2013), and other relevant professionals or local health care providers (CPS, 2019; NAS, 2003; NICE, 2017; NY, 2017; CRC, 2018), with the family's consent. The CRC (2018), UC (2013) and MDMH (2010) guidelines also recommended sharing the report with service providers or funding agencies when appropriate.

\section{Gaps or Inconsistencies in Recommendations}

\section{Who Should be Present at Feedback?}

The CRC (2018) and MDMH (2010) guidelines recommended one clinician conduct feedback, while the PSI (2010) and NAS (2003) guidelines recommended two. The HAS (2018) and NAS (2003) guidelines specified the/a clinician should be the medical professional, while the PSI (2010) guideline stipulated one should be a psychologist. The CDDS (2002) guideline suggested the communication style of the clinicians should be considered and to avoid a large number of clinicians being present at feedback as this may overwhelm families, however did not quantify a "large number" (p. 71).

The CPS (2019), NICE (2017) and CRC (2018) guidelines recommended discussing findings with the child or young person if appropriate. One guideline recommended simply having the child present in the room or building during feedback (PSI, 2010). The SIGN (2016) and UC (2013) guidelines suggested the child should not be present during feedback, and the SIGN (2016) guideline recommended when feasible/appropriate to arrange childcare for the family. The UC (2013) guideline suggested conducting a second 
Table 3 Quality analysis: summary of AGREE II domain scores, guideline ranking and overall recommendation

\begin{tabular}{|c|c|c|c|c|c|c|c|c|}
\hline $\begin{array}{l}\text { Guideline } \\
\text { (year) }\end{array}$ & $\begin{array}{l}\text { Domain 1: } \\
\text { scope and } \\
\text { purpose }\end{array}$ & $\begin{array}{l}\text { Domain 2: } \\
\text { stakeholder } \\
\text { involvement }\end{array}$ & $\begin{array}{l}\text { Domain 3: } \\
\text { rigor of devel- } \\
\text { opment }\end{array}$ & $\begin{array}{l}\text { Domain 4: } \\
\text { clarity of } \\
\text { presentation }\end{array}$ & $\begin{array}{l}\text { Domain 5: } \\
\text { applicabil- } \\
\text { ity }\end{array}$ & $\begin{array}{l}\text { Domain 6: } \\
\text { editorial inde- } \\
\text { pendence }\end{array}$ & $\begin{array}{l}\text { Overall guide- } \\
\text { line assess- } \\
\text { ment }\end{array}$ & $\begin{array}{l}\text { Recommenda- } \\
\text { tion }\end{array}$ \\
\hline CRC (2018) & 94 & 100 & 98 & 94 & 92 & 100 & 100 & $\begin{array}{l}\text { Strongly rec- } \\
\text { ommend }\end{array}$ \\
\hline NICE (2017) & 100 & 100 & 98 & 97 & 85 & 92 & 100 & $\begin{array}{l}\text { Strongly rec- } \\
\text { ommend }\end{array}$ \\
\hline SIGN (2016) & 94 & 86 & 85 & 94 & 73 & 100 & 92 & $\begin{array}{l}\text { Strongly rec- } \\
\text { ommend }\end{array}$ \\
\hline NZ (2016) & 97 & 97 & 92 & 97 & 50 & 71 & 75 & $\begin{array}{c}\text { Strongly rec- } \\
\text { ommend }\end{array}$ \\
\hline NY (2017) & 86 & 86 & 76 & 83 & 23 & 79 & 75 & $\begin{array}{c}\text { Strongly rec- } \\
\text { ommend }\end{array}$ \\
\hline HAS (2018) & 97 & 92 & 57 & 81 & 35 & 67 & 75 & $\begin{array}{c}\text { Strongly rec- } \\
\text { ommend }\end{array}$ \\
\hline CPS (2019) & 47 & 50 & 18 & 67 & 15 & 100 & 42 & $\begin{array}{l}\text { Recommend } \\
\text { with altera- } \\
\text { tions }\end{array}$ \\
\hline UC (2013) & 72 & 78 & 28 & 67 & 23 & 25 & 42 & $\begin{array}{l}\text { Recommend } \\
\text { with altera- } \\
\text { tions }\end{array}$ \\
\hline $\begin{array}{r}\text { MDMH } \\
(2010)\end{array}$ & 67 & 89 & 20 & 64 & 40 & 8 & 42 & $\begin{array}{l}\text { Recommend } \\
\text { with altera- } \\
\text { tions }\end{array}$ \\
\hline NAS (2003) & 61 & 67 & 22 & 53 & 38 & 25 & 42 & $\begin{array}{l}\text { Recommend } \\
\text { with altera- } \\
\text { tions }\end{array}$ \\
\hline AAN (2000) & 56 & 39 & 46 & 47 & 13 & 54 & 42 & $\begin{array}{l}\text { Recommend } \\
\text { with altera- } \\
\text { tions }\end{array}$ \\
\hline $\begin{array}{l}\text { AMS-MOH } \\
(2010)\end{array}$ & 58 & 53 & 30 & 75 & 21 & 8 & 33 & $\begin{array}{l}\text { Recommend } \\
\text { with altera- } \\
\text { tions }\end{array}$ \\
\hline AAP (2007) & 33 & 31 & 13 & 64 & 42 & 33 & 33 & $\begin{array}{l}\text { Recommend } \\
\text { with altera- } \\
\text { tions }\end{array}$ \\
\hline $\begin{array}{r}\text { AACAP } \\
(2014)\end{array}$ & 33 & 33 & 35 & 75 & 2 & 25 & 42 & $\begin{array}{l}\text { Recommend } \\
\text { with altera- } \\
\text { tions }\end{array}$ \\
\hline AE (2019) & 28 & 36 & 11 & 28 & 13 & 83 & 17 & $\begin{array}{l}\text { Do not recom } \\
\text { mend }\end{array}$ \\
\hline CDDS (2002) & 53 & 50 & 10 & 61 & 21 & 0 & 33 & $\begin{array}{l}\text { Do not recom } \\
\text { mend }\end{array}$ \\
\hline PSI (2010) & 69 & 33 & 10 & 53 & 2 & 4 & 41 & $\begin{array}{l}\text { Do not recom- } \\
\text { mend }\end{array}$ \\
\hline
\end{tabular}

Bold values represent the overall guideline assessment score

Guidelines are displayed in descending order of their total average domain score. Strongly recommend=at least four of six domain scores were greater than $60 \%$. Recommend with alterations = at least four of six domain scores were between 30 and $60 \%$, or at least two domain scores were more than $60 \%$. Do not recommend = if four or more domain scores were less than $30 \%$

feedback session for adolescents to attend. The NZ (2016) guideline suggested the wishes, privacy and support needs of older teenagers should be considered when involving family in the feedback session.

Only three guidelines recommended providing additional feedback to the child's professional supports or educators with parents' consent and when considered appropriate (CDDS, 2002; NZ 2016; NICE, 2017). The CDDS (2002) guideline suggested inviting supports such as educational personnel to the feedback session. The NICE (2017) guideline encouraged providing additional feedback to schools 
Table 4 details of feedback recommendations and evidence reported in each guideline

\begin{tabular}{ll}
\hline Guideline & Feedback section title (page numbers) \\
\hline CRC (2018) & Sharing Findings (pp. 47-48) \\
NICE (2017) & Communicating Diagnosis to the Family (pp. 120-130)
\end{tabular}

SIGN (2016) Provision of Information (pp. 42-43)

NZ (2016) Formulation, disclosure of diagnosis and post-diagnosis support (p. 54-55)

NY (2017)

HAS (2018)

Engaging Families as Partners in Diagnostic Assessment and Evaluation (pp. 47-50)

Announcement of the Medical Diagnosis and Information for Families (pp. 23-24)

CPS (2019) Communicating ASD Diagnostic Assessment Findings (pp. 448-449)

UC (2013)

Evaluation Results (pp. 46-51)

MDMH (2010) Formulating Conclusions and Presenting Information (pp. 75-76)

NAS (2003)

CDDS (2002)

Outcome of the ASD Assessment Process (pp. 38-40)

Formulation, Presentation and Documentation of Findings (pp. 71-75)

PSI (2010) Feedback to Parents (pp. 19-21)
Level of evidence used to form feedback recommendations

Grade 1 a — "Body of evidence is consistent across numerous evidence sources, and there is excellent support from experts for recommendation(s)" (Whitehouse et al., 2018)

"Nine studies were included in the review. The evidence identified was qualitative, based on small scale studies, all from the UK. It reported the views of parents only and the quality was very low"

"Recommended best practice based on the clinical experience of the guideline development group."

"A limited amount of evidence was identified"

Grade B-"The recommendation is supported by FAIR evidence (based on studies that are mostly valid, but there are some concerns about the volume, consistency, applicability and/or clinical relevance of the evidence that may cause some uncertainty, but are not likely to be overturned by other evidence)." (p. 7)

Grade C- - The recommendation is supported by EXPERT OPINION only (from external opinion, published or unpublished, eg, consensus guidelines)."

Good Practice Points - "Where no evidence is available, best practice recommendations are made based on the experience of the Guideline Development teams or feedback from consultation within New Zealand. “( p. 7)

Based on the opinion of panel members about current best practices

Not provided

Not provided

Not provided

Not provided

Not provided

Not provided

Not provided

${ }^{a}$ The CRC (2018) guideline modified the National Health and Medical Research Council approach to grading recommendations "Due to a paucity of high-level evidence identified through the systematic literature review, this modified approach allowed supporting evidence from community consultation activities and international guidelines to be reviewed alongside the research evidence from peer-reviewed journals" (Whitehouse et al., 2018)

and educators in order to contribute to the child's "individual education plan and needs-based management plan" (p. 21).

\section{Timing of feedback}

Only the NICE (2017) guideline recommended a set time frame for the follow up session, suggesting it occur within six weeks of the end of the assessment.

\section{Mode of Delivery}

Only two guidelines (CPS, 2019; CRC, 2018) provided recommendations regarding telehealth as an alternative method for providing feedback. The CRC (2018) guideline stated when telehealth is used it is critical another local professional is physically with the client during the meeting to provide support (p. 47).

\section{Special Considerations for Feedback}

Only three guidelines specifically recommended the feedback session be conducted in the caregiver's first language and interpreter services be utilised (CPS, 2019; UC, 2013; CRC, 2018). The UC (2013) guideline specified an independent third-party interpreter should be used. Guidelines published by the CRC (2018), SIGN (2016), NAS (2003) 


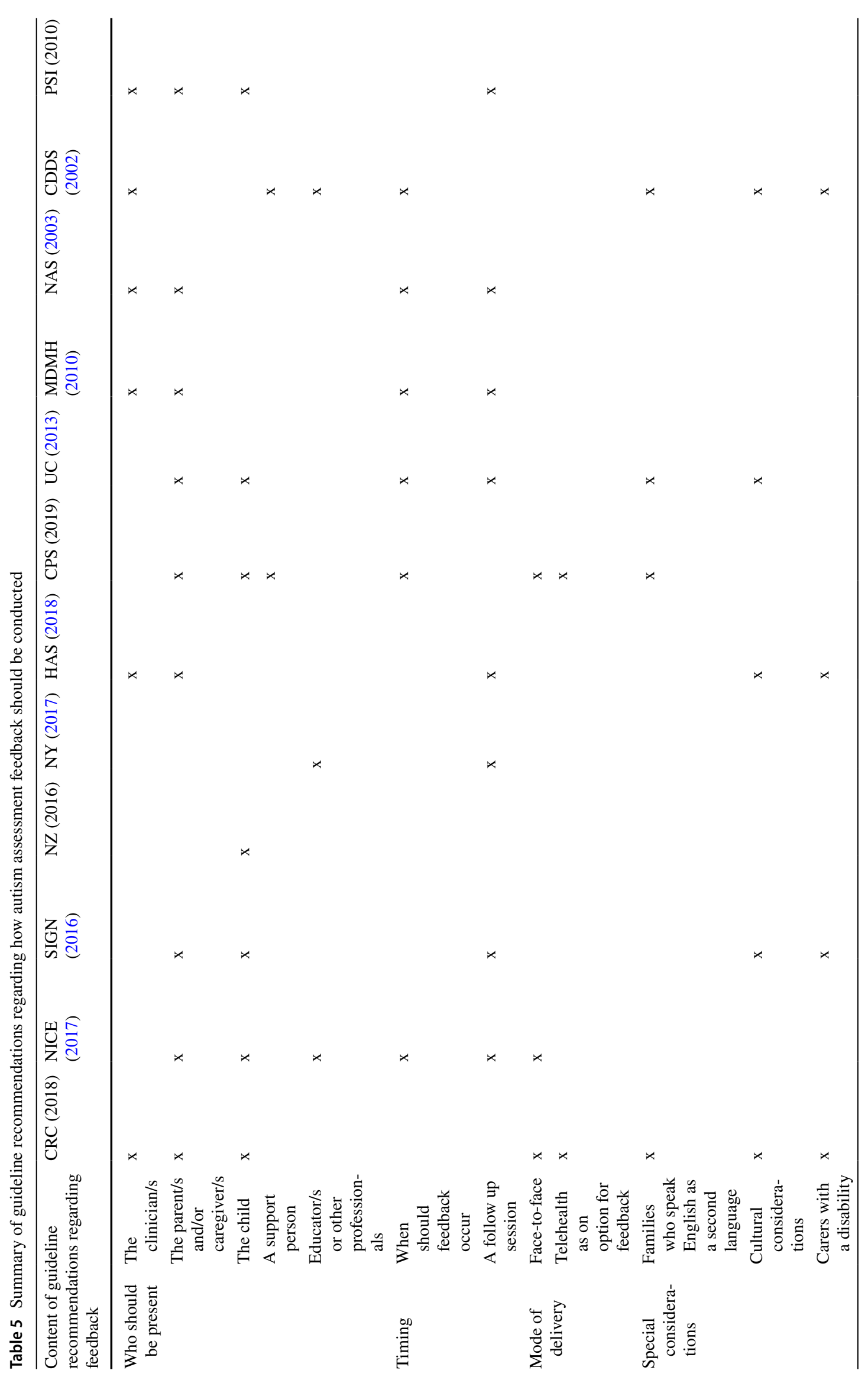




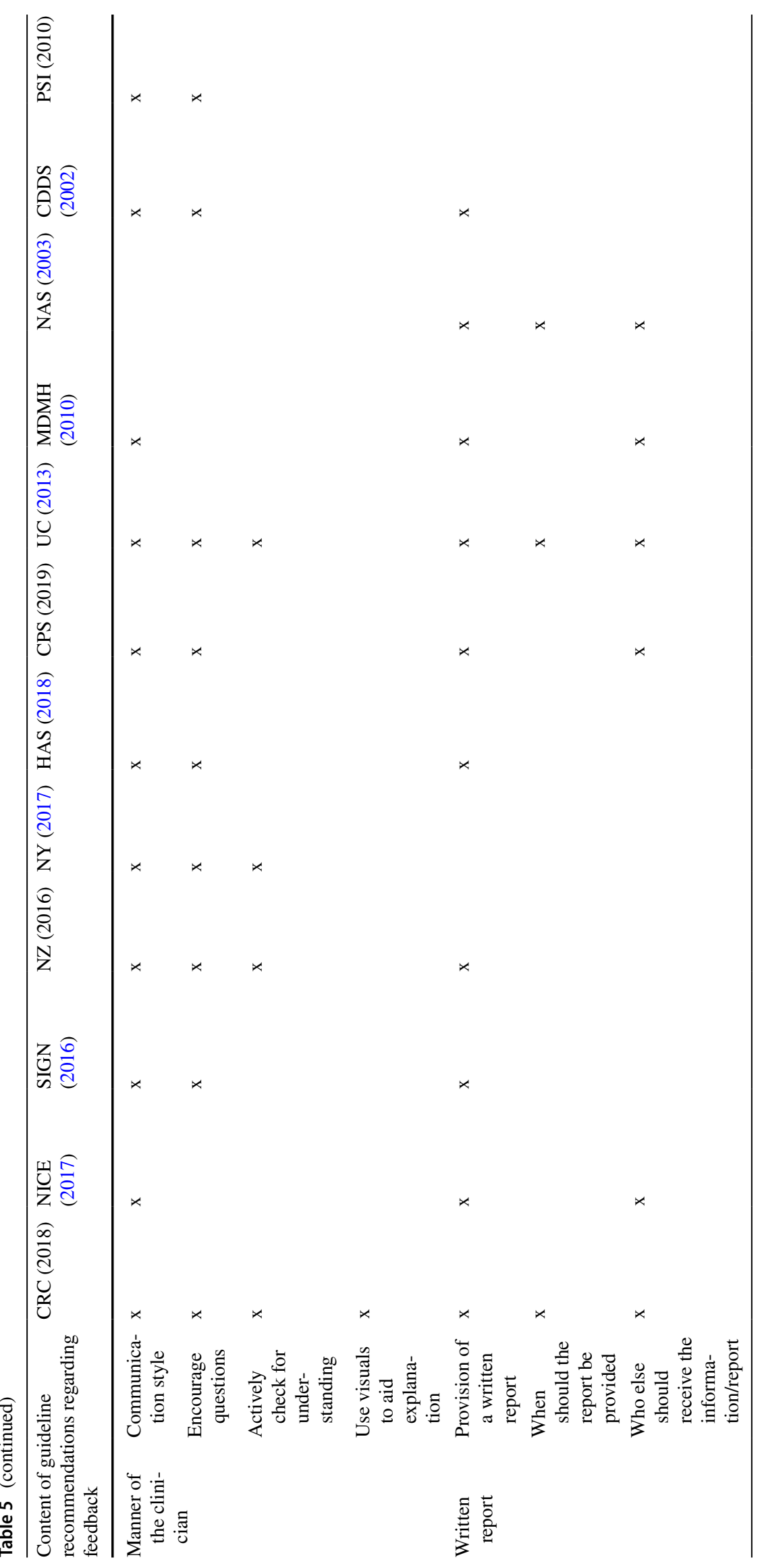


and CDDS (2002) recommended written material be translated for families from non-English speaking backgrounds. The CRC (2018) guideline recommended families receive cultural support from a community member or appropriate professional if it is requested or perceived as potentially beneficial.

Four guidelines addressed concerns regarding the delivery of feedback to carers with differing abilities. These guidelines emphasised that information should be conveyed in a manner appropriate for the carer's verbal and written proficiency (CRC, 2018), educational background, coping styles (CDDS, 2002) and overall ability level (SIGN, 2016). The HAS (2018) guideline explicitly stated additional attention is required when the "parents themselves are disabled" (p. 24).

\section{Manner of the Clinician}

Only one guideline suggested (a) considering answering questions from the child or their brothers/sisters at a follow up session (HAS, 2018); (b) that clinicians first endeavour to gauge caregivers' level of understanding about autism before adding additional information (SIGN, 2016) and (c) using visual aids or strategies to enhance understanding and support explanations at feedback CRC (2018). A minority recommended using reflective listening practices and checking in with families throughout the session (CRC, 2018, NY, 2017, UC, 2013).

\section{The Written Report}

Three guidelines recommended different time points for the report to be provided, including at the feedback session (UC, 2013), or within 3 months (CRC, 2018) or 17 weeks (NAS, 2003) of the first assessment. The NAS (2003) guideline suggested families contribute to the report and identify any factual errors at the feedback session.

\section{Recommendations Regarding What Information to Share}

Table 6 provides a visual representation of the guideline recommendations regarding information that should be shared at feedback or in the accompanying report. Only recommendations provided in the "feedback" or report sections of the guideline are included in these results.

\section{Consistent Recommendations}

\section{The Diagnostic Process}

Seven guidelines suggested providing families with information about the assessments conducted (CRC, 2018; SIGN,
2016; CPS, 2019; UC, 2013; MDMH, 2010; CDDS, 2002; PSI, 2010). Four of these seven provided specific recommendations, suggesting offering information about the professionals who conducted the assessments (CPS, 2019; SIGN, 2016; CRC, 2018), the names of the assessment tools (PSI, 2010; CRC, 2018) and descriptions of what the tools measure (CRC, 2018).

\section{Autism}

Eleven of the guidelines recommended discussing general information about autism (NICE, 2017; SIGN, 2016; NZ; 2016, HAS, 2018; UC, 2013; PSI, 2010) and/or providing families with resources to access this information (NY, 2017; CPS, 2019; UC, 2013; MDMH, 2010; NAS, 2003; CDDS, 2002; PSI, 2010).

\section{The Child's Presentation}

Nine guidelines made simple general recommendations to share information about test results or functioning levels with families (CRC, 2018; NICE, 2017; SIGN, 2016; NY, 2017; HAS, 2018; CPS, 2019; UC, 2013; MDMH, 2010; CDDS, 2002). Seven guidelines recommended emphasising the child's individual strengths and weaknesses at feedback (CRC, 2017; NZ, 2016; NY, 2017; HAS, 2018; UC, 2013; MDMH, 2010; CDDS, 2002). The MDMH (2010) guideline indicated that areas of typical development can be highlighted as strengths, and the CRC (2018) guideline suggested strengths could be activity or character related. Three of these seven guidelines proposed discussing the child's potential level of functioning with adequate supports or how intervention might help capitalise on their strengths (HAS, 2018; NY, 2017; CRC, 2018). Guidelines also recommended discussing the child's "highest priority support needs" (CRC, 2018) including learning, communication or social challenges (NY, 2017) and maladaptive behaviours (MDMH, 2010).

\section{Recommendations and Referrals}

Half of the guidelines recommended clinicians provide families with specific referrals to local professional supports (CPS, 2019; NAS, 2003; NY, 2017; MDMH, 2010; UC, 2013; CRC, 2018). The CDDS (2002) guideline suggested discussing the efficacy and empirical support of the different intervention approaches available. Three guidelines advised that formal supports should be specifically tailored to the child and their unique needs (CPS, 2019; CRC, 2018; HAS, 2017). The SIGN (2016) guideline provided the greatest detail on social support recommendations, emphasising the importance of social and family networks. Both the SIGN (2016) and MDMH (2010) guidelines advised discussing 


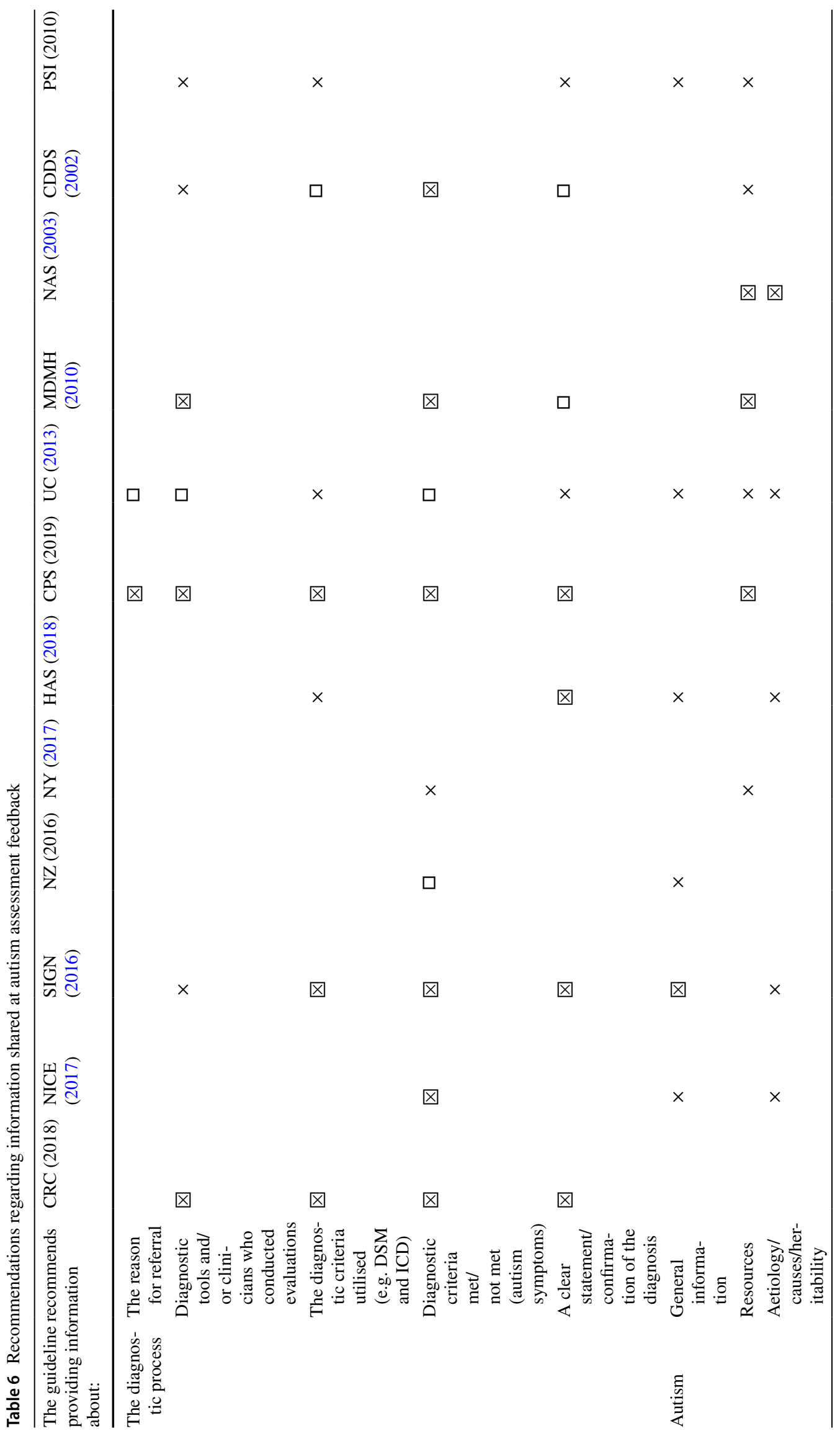




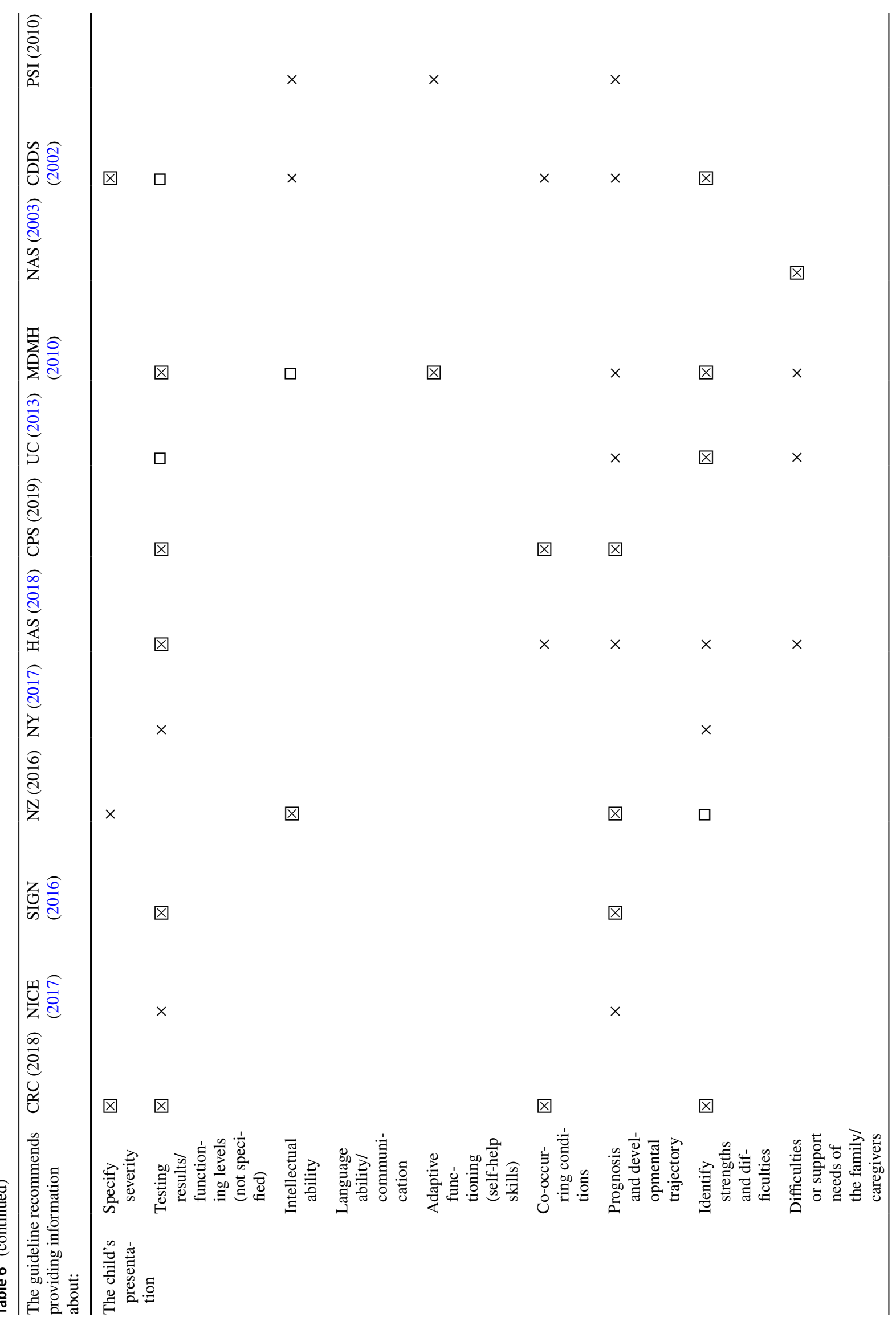




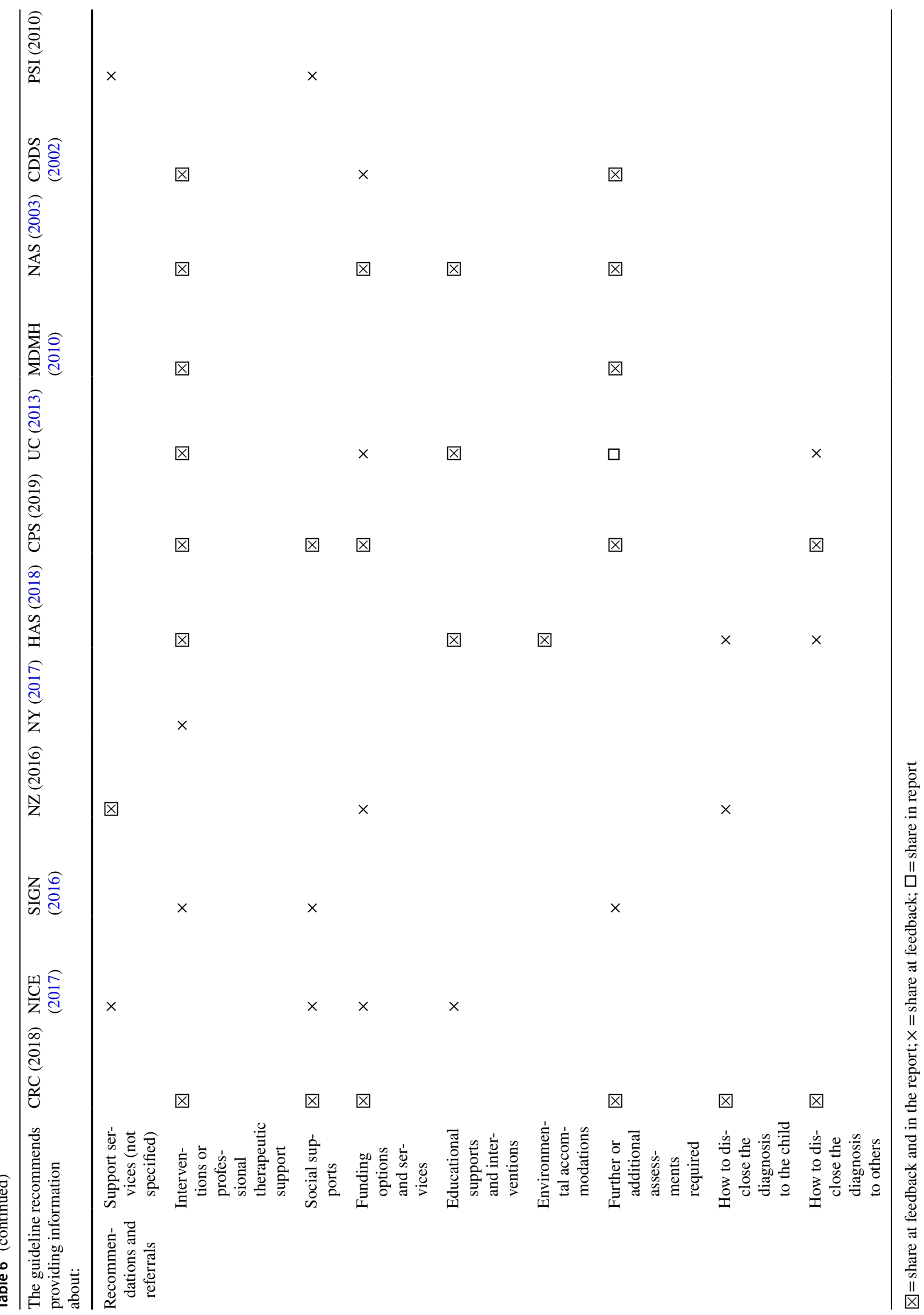


with families that carer advocacy can play a crucial role in intervention outcomes. Three guidelines suggested clinicians recommend parent advocacy groups (CPS, 2019; NICE, 2017; UC, 2013).

The NICE (2017) and UC (2013) guidelines suggested recommending organisations that can provide support and advice on welfare benefits and entitlements, while others recommended the diagnosing clinician provide this information directly at feedback (CRC 2018; NZ 2016). Three guidelines suggested this information should also be given to families as resources during the session (CPS, 2019; CDDS, 2002; NAS, 2003). Seven guidelines recommended sharing information about further assessments that may be required (SIGN, 2016; UC; 2013, MDMH, 2010; NAS, 2003) or suggested timeframes for reassessments (CRC, 2018; CDDS, 2019).

\section{Gaps or Inconsistencies in Recommendations}

\section{The Diagnostic Process}

Only the CPS (2019) guideline recommended discussing with families the reason for the child's referral. The UC (2013) recommended including this information in the report.

\section{Autism}

One guideline recommended offering families basic information on current knowledge about the causation of autism (SIGN, 2016), while another endorsed reassuring carers that their child's autism diagnosis is not their fault (UC, 2013). The NICE (2017) and HAS (2018) guidelines recommended discussing with families the risk of autism occurring in siblings or future children. The HAS (2018) and NAS (2003) guidelines also recommended families should be referred for genetic predisposition testing and counselling if they have or are planning on having more children.

\section{The Child's Presentation}

Of the 10 guidelines that utilised DSM-5 (APA, 2013) criteria, only the CRC (2018) and NY (2016) guidelines specifically recommended sharing information about the diagnosis severity with families at feedback. The CDDS guideline published in 2002 (i.e., before the introduction of the DSM-5), also recommended explaining to parents "where the child fits on the autism spectrum" (p. 72) and including the recommended severity rating applied to the diagnosis in the report. Only four guidelines recommended sharing information about intellectual functioning and highlighting the interplay between autism and intelligence. Only two guidelines recommended discussing adaptive functioning (MDMH,
2010; PSI, 2010), and none of the guidelines specifically recommended highlighting communication ability, as a formal assessment or general observation.

The UC (2013), CDDS (2002) and PSI (2010) guidelines cautioned against providing definitive long-term predictions about the child and suggested topics such as independent living and employment are not appropriate to discuss at feedback unless the child is of "transition age or older (e.g., age 13 and older)" (CDDS, 2002, p. 49). Other guidelines advised clinicians be prepared to answer questions about prognosis (PSI, 2010; MDMH, 2010). The NZ (2016) guideline suggested clinicians consider that phenotypic expressions of autism vary with age and that prognosis is equally influenced by a child's general intelligence.

Four guidelines recommended discussing difficulties or needs of the family and three of these emphasised reviewing carers' stress levels, quality of life and any other issues they may be experiencing at feedback (HAS, 2018; MDMH, 2010; UC, 2013).

\section{Recommendations and Referrals}

The MDMH (2010) guideline was the only guideline that recommended providing immediate advice for pressing concerns and behavioural challenges. Some guidelines recommended referring families to special education services (NAS, 2003; UC, 2013) or organisations that can provide information on educational support (NICE, 2017). The HAS (2018) guideline stipulated feedback of an autism diagnosis must be associated with the development of a personalised plan for educational intervention and suitable accommodations in the school environment for the child.

Only three guidelines recommended discussing with carers if, when and how they should disclose the diagnosis to their child. Two of these specified this was an important/ essential element of feedback with families (HAS, 2018; SIGN, 2016). The HAS (2018) guideline also recommended discussing how/when to explain the diagnosis with siblings, extended family members and friends. They recommended providing "tools (such as informational brochures) to guide parents in their process of announcing the diagnosis" (p. 24) to others. The UC (2013) guideline suggested emphasising the importance of communication and collaboration across all those who will be involved with helping and supporting the child and their family.

\section{Discussion}

Seventeen guidelines were included in this review, but five did not contain recommendations for feedback. The recommendations for feedback published within twelve guidelines, from eight different countries were analysed. Previous 
reviews of autism assessment guidelines have highlighted similarities and inconsistencies between recommendations regarding various elements of the autism assessment process (Hayes et al., 2018; Penner et al., 2018). This scoping review adds to the existing knowledge by drawing attention to the recommendations regarding an essential element of the assessment process, the feedback of results and disclosure of diagnosis to caregivers.

The first objective of this review was to assess the quality of autism assessment guidelines that provide recommendations for feedback. Only five guidelines provided information regarding the methodology and evidence quality used to form these recommendations. The majority of the recommendations for feedback were based on the opinions of the development groups, with most of these guidelines reported finding limited to no evidence, or evidence of "very low" (NICE, 2017, p. 120) to "fair" (NZ, 2016, p. 7) quality to support them. The quality of the information produced by an expert panel is dependent on the information inputs and methods used to reach the consensus (Jorm, 2015). When experts are informed by professional experience, as well as high quality information such as the results of systematic reviews or randomised controlled trials, the quality of the consensus results increases (Jorm, 2015). Likewise, a formal method of reaching consensus, such as the Delphi method, is more likely to produce a true reflection of the opinions of the entire group (Hohmann et al., 2018; Jorm, 2015). Few guidelines within this review reported using consensus agreement of expert opinions, and only one utilised a formal, but different, method. Similarly, many relied heavily on the professional background of the guideline development groups to inform recommendations for feedback. Formal consensus methods can produce higher quality evidence and are well suited to producing health guidelines (de Meyrick, 2003; Jorm, 2015), however the methods used to form recommendations for feedback within these guidelines were of a low standard, and therefore should be interpreted with caution.

The second objective of this investigation was to determine what is currently considered best practice for feedback of autism assessment results and diagnosis. Our review revealed there were few recommendations for feedback provided, and many lacked sufficient detail to establish what an overall best practice autism feedback session would involve. The majority of guidelines generally recommended one or multiple clinicians conduct feedback with the caregiver/s without delay. They recommended clinicians consider their communication style and provide families with a written report. Guidelines encouraged clinicians to provide information regarding the diagnostic process, autism as a condition, the child's presentation and recommendations and referrals for support. Inconsistencies were observed in the specific details of recommendations, and the gaps across guidelines suggest there is no current universal standard practice for autism diagnostic assessment feedback.

The final objective of this review was to identify gaps or inconsistencies in feedback recommendations that may require further investigation. While contradictions in recommendations between guidelines were rare, recommendations considered important in some guidelines (for example, offering a follow up session post feedback) were omitted from other guidelines. The reasons for some guidelines omitting certain feedback recommendations is unclear. Possible explanations include the development group not deeming specific feedback recommendations to be important, correct or feasible, or the specific feedback recommendations were simply overlooked. Such omissions may have significant clinical implications, with important elements of feedback overlooked by clinicians who refer to a single guideline to inform their practice. Indeed, Clinicians may not consider the potential benefits of offering follow up sessions to families, despite other reputable guidelines (NICE, 2017) and research evidence (Crane et al., 2016; Mulligan et al., 2012) suggesting this clinical practice may be beneficial for families.

Only two guidelines provided recommendations for conducting feedback via telehealth in the event that an in-person meeting cannot occur. In recent times the number of clinicians offering telehealth services has risen significantly, largely due to the impacts of the COVID-19 pandemic (Duckett, 2020; Wosik, 2020). With funding models such as Medicare in Australia adjusting to cover remote or online consultations, clinicians may need to seek advice and guidance on how to conduct feedback sessions via telehealth and identify any important differences compared to traditional practice (Duckett, 2020). Autism assessment guidelines do not currently provide sufficient detail or evidence synthesis to guide clinicians on this practice.

Many carers report feeling stressed, isolated and depressed in the immediate period after receiving an autism diagnosis for their child (Casey et al., 2012; Crane et al., 2018; Taylor \& Warren, 2012). Only two guidelines recommended clinicians encourage parents to invite a support person with them to feedback. Additionally, none of the guidelines addressed how to handle situations of separated carers who cannot attend feedback together, or situations of blended families. Research has suggested that having a support person present at autism assessment feedback can improve an unaccompanied parent's satisfaction with the session (Hennel et al., 2016), and generic models of "breaking bad news" often suggest the patient, or carer bring a support person with them when assessment results are being communicated (Harrison \& Walling, 2010; Liddicoat, 2018).

Few guidelines recommended considering tailored educational supports or accommodations for the child or involving educators in the feedback process, despite parents 
listing school supports as an important factor in their decision to seek assessment (Bent et al., 2015; Ruiz Calzada et al., 2012). An Australian study highlighted that despite parent's desire to receive information about school supports during feedback, the majority did not receive it (Hennel et al., 2016). Teachers are often responsible for implementing many of the recommendations provided by diagnosing clinicians (Barrett, 2019) and value the opportunity to share knowledge with clinicians (Pelco et al., 2009). For an assessment and diagnosis to be beneficial for a child, it is critical parents and teachers receive and understand tailored information about a child's unique strengths and weaknesses and how to best support the individual (Andersson et al., 2014). Emphasising this within clinical practice guidelines may help increase this practice and have potential implications on teacher's adoption of clinician's recommendations (Barrett, 2019).

The DSM-5 (APA, 2013) stipulates an autism diagnosis should specify if there is accompanying intellectual or language impairment. Only one of the eight guidelines that utilised DSM-5 criteria, however, specifically addressed discussing intellectual ability at feedback. None mentioned discussing language assessments or general language ability. Similarly, none of the guidelines published after 2013 specifically mentioned discussing adaptive functioning, despite "clinically significant impairment in social, occupational or other areas of current functioning" being a requirement for autism diagnosis according to DSM-5 criteria (APA, 2013). These factors influence a child's functioning in the present and potential for functioning in the future (Kanne et al., 2011; Kraper et al., 2017). Therapeutic and educational training for individuals with autism is increasingly focusing on improving adaptive behaviours and participation as per the International Classification of Functioning framework (World Health Organization, 2007), making it important to discuss a child's adaptive functioning at feedback. Additionally, without explaining how these areas of functioning and ability impact all children, including those with autism, families may find it difficult to completely understand their child's presentation.

In general, there were a lack of specific recommendations regarding what to discuss at feedback within guidelines. Often vague or broad statements such as "discuss results", "communicate assessment findings" or "recommend supports" were provided. This may reflect the lack of empirical evidence to guide what is considered best practice and the heterogeneous nature of autism (Penner et al., 2018). Guideline development groups may have found it difficult to provide details around which topics are most important to discuss at feedback, as this may vary depending on the child. Parents have reported wanting more information from the diagnosing clinician (Hennel et al., 2016; Potter, 2017) and have found it challenging to identify evidence based information when forced to conduct their own research online (Adler et al., 2015). Greater detail is required in these guidelines to ensure clinicians are aware of all the information needs of families at the time of diagnosis.

The reviewed guidelines often emphasised the need for feedback to be individualised to the child's presentation. Many recommended that clinicians adopt a strengths-based approach to feedback and discuss with carers the child's unique set of personal assets and challenges. They also advised that support recommendations be tailored to the child. Considering a child's strengths as well as their weaknesses across all areas of functioning could lead to more informed interventions and a more balanced understanding of the child. Providing a tailored feedback session, and addressing all functioning rather than just autism symptomatology, could also potentially lead to more individualised intervention and support (Ure et al., 2018).

This review was not without limitations. First, only guidelines published in English were included. Whilst English speaking countries were considered likely to have similar approaches to health care and therefore produce comparable guidelines, high quality guidelines and recommendations for feedback published in other languages are likely to have been missed. Second, although a research librarian was consulted to construct search terms and minimise the possibility of missing guidelines, and multiple authors screened and appraised guidelines, and consulted on data extraction tables, only the first author extracted data for the review, which may have resulted in unintentional biases. A third limitation of this study was the adaptation of the AGREE-II tool to consider all questions in the context of assessment. This adaptation means scores for domains three, four and the overall measure may not be directly comparable to the AGREE-II scores (Brouwers et al., 2010) generated in other studies. There is also no validated cut-off score or pattern of domain scores established for the AGREE-II to differentiate between high and poor quality guidelines (Brouwers et al., 2010). As per the recommendation of the instrument developers, we interpreted scores using categorisation of domains similar to another recently published study (Amer et al., 2019). Other reviews may establish different parameters for cut-off scores, limiting the ability to make direct comparisons.

There are strengths and weaknesses to reviewing only one section of guidelines. To our knowledge, this is the first study to examine autism guidelines with a focus on the feedback of assessment results. By focusing on a single element of the assessment process we were able to investigate all aspects of feedback in great detail but it is possible that information relevant to the themes explored in this review published in other sections of guidelines may have been missed. Additionally, it is unclear if some recommendations 
were not explicitly detailed in certain guidelines because they were implied best practice, such as recommendations regarding clinician's manner. We were only able to analyse recommendations that had been explicitly documented.

This review highlights a need for further attention to be given to feedback processes and the way autism diagnoses are communicated. The majority of recommendations for feedback published within the reviewed guidelines were based primarily on the opinions of the individual guideline's development group and were achieved using informal methods of reaching consensus. A number of gaps and inconsistencies were observed between guidelines and recommendations often lacked detail. It is highly probable that there are currently great practice variations across clinicians from all settings, due to the lack of clear and detailed guidance regarding feedback, and that many families may currently be receiving less than optimal feedback. Before assessing current practice and making recommendations for improvement, it is imperative we establish what best practice involves. In a similar manner to other research into the disclosure of diagnoses of dementia (Lecouturier, 2008) and Down syndrome (Sheets et al., 2011), establishing specific guidelines for feedback of an autism diagnosis, using formal methods of reaching group consensus between expert clinicians and informed by high quality empirical evidence, could be the first step in greatly improving clinicians and family's experiences.

Future research should endeavour to explore the impact of improving various elements of feedback and enhancing experiences and outcomes for families receiving an autism diagnosis. For example an empirical study could assess the effects of including educators at feedback, or providing them with their own follow up sessions. A specific focus on the identified gaps in guideline recommendations could be beneficial, as could investigations into practices in other countries not explored in this review. Detailed guideline recommendations could initially be used to train and assess clinicians working within local settings, and if successful outcomes resulted, this information could be used to inform international guidelines and training programs across the worldwide autism community. It is hoped that bringing more attention to research into autism feedback, will lead to increased attention to this part of the assessment and that this review and future research will encourage clinicians to reflect on their own practices and consider areas for improvement.

In conclusion, most guidelines for the assessment and diagnosis of autism in children include recommendations for feedback of results and diagnosis to families and those involved with supporting and caring for the child. The types and content of recommendations vary considerably between guidelines, although overall they consistently make recommendations regarding who should attend, the timing and mode of delivery, how the clinician should conduct themselves and what should be discussed and included in the report. The variations are likely due to the fact that the majority of recommendations for feedback were created based on the expert opinions of the respective guideline development groups and the limited empirical research that exists within this area. There is evidently a need for further research and higher quality guidelines focusing on this important element of the autism assessment process, which could have potential implications for improved practice.

Supplementary Information The online version contains supplementary material available at https://doi.org/10.1007/s10803-021-05067-9.

Acknowledgements The authors wish to thank Ms Georgina Werninghaus for her assistance in the appraisal of guideline documents.

Author Contributions EP, KW, AU and NF conceptualised the study. EP conducted the literature search and EP, SM and GW completed all data extraction and analysis. EP completed the data interpretation and drafted the manuscript. EP, $\mathrm{KW}, \mathrm{AU}, \mathrm{NF}$ and SM revised drafts and approved the final version for publication.

\section{References}

Abbott, M., Bernard, P., \& Forge, J. (2013). Communicating a diagnosis of autism spectrum disorder-A qualitative study of parents' experiences. Clinical Child Psychology and Psychiatry, 18, 370-382. https://doi.org/10.1177/1359104512455813

Academy of Medicine Singapore. (2010). Academy of Medicine Singapore-Ministry of Health clinical practice guidelines: Autism Spectrum Disorders in pre-school children. Singapore Medical Journal, 51, 255-263

Adler, K., Salanterä, S., Leino-Kilpi, H., \& Grädel, B. (2015). An integrated literature review of the knowledge needs of parents with children with special health care needs and of instruments to assess these needs. Infants \& Young Children, 28, 46-71. https:// doi.org/10.1097/IYC.0000000000000028

Amer, Y. S., et al. (2019). Appraisal of clinical practice guidelines for the management of attention deficit hyperactivity disorder (ADHD) using the AGREE II Instrument: A systematic review. PLoS ONE. https://doi.org/10.1371/journal.pone.0219239

American Psychiatric Association. (2013). Diagnostic and statistical manual of mental disorders. (5th ed.). American Psychiatric Association.

Andersson, G. W., Miniscalco, C., \& Gillberg, C. (2014). Preschoolers assessed for autism: Parent and teacher experiences of the diagnostic process. Research in Developmental Disabilities, 35, 3392-3402. https://doi.org/10.1016/j.ridd.2014.08.027

Autism Spectrum Disorders Special Interst Group. (2010). Best practice guidelines for the assessment and diagnosis of autistic spectrum disorders for children and adolescents (birth to 18 years). The Psychological Society of Ireland.

Barrett, F. (2019). Teacher adherence to school-based psychoeducational report recommendations. University of Calgary 
Barthélémy, C., Fuentes, J., Howlin, P., \& van der Gaag, R. (2019). People with autism spectrum disorder. Identification, understanding, intervention. Brussles, Belgium: Autism-Europe.

Bennett, K., Courtney, D., Duda, S., Henderson, J., \& Szatmari, P. (2018). An appraisal of the trustworthiness of practice guidelines for depression and anxiety in children and youth. Depression and Anxiety, 35, 530-540. https://doi.org/10.1002/da.22752

Bent, C. A., Dissanayake, C., \& Barbaro, J. (2015). Mapping the diagnosis of autism spectrum disorders in children aged under 7 years in Australia, 2010-2012. Medical Journal of Australia, 202, 317-320. https://doi.org/10.5694/mja14.00328

Brian, J. A., Zwaigenbaum, L., \& Ip, A. (2019). Standards of diagnostic assessment for autism spectrum disorder. Paediatrics \& Child Health, 24, 444. https://doi.org/10.1093/pch/pxz117

Brogan, C. A., \& Knussen, C. (2003). The disclosure of a diagnosis of an autistic spectrum disorder: Determinants of satisfaction in a sample of Scottish parents. Autism, 7, 31-46. https://doi.org/10. $1177 / 1362361303007001004$

Brouwers, M. C., et al. (2010). AGREE II: Advancing guideline development, reporting and evaluation in healthcare. Canandia Medical Association Journal. https://doi.org/10.1503/cmaj.090449

California Department of Developmental Services, Northern California Autism Collective (2002). Autism spectrum disorders: Best practice for screening, diagnosis and assessment.

Carlsson, E., Miniscalco, C., Kadesjö, B., \& Laakso, K. (2016). Negotiating knowledge: Parents' experience of the neuropsychiatric diagnostic process for children with autism. International Journal of Language \& Communication Disorders, 51, 328-338. https:// doi.org/10.1111/1460-6984.12210

Casey, L. B., Zanksas, S., Meindl, J. N., Parra, G. R., Cogdal, P., \& Powell, K. (2012). Parental symptoms of posttraumatic stress following a child's diagnosis of autism spectrum disorder: A pilot study. Research in Autism Spectrum Disorders, 6, 1186-1193. https://doi.org/10.1016/j.rasd.2012.03.008

Crane, L., Batty, R., Adeyinka, H., Goddard, L., Henry, L. A., \& Hill, E. L. (2018). Autism diagnosis in the United Kingdom: Perspectives of autistic adults, parents and professionals. Journal of AUTISM and Developmental Disorders, 48, 3761. https://doi.org/ 10.1007/s10803-018-3639-1

Crane, L., Chester, J. W., Goddard, L., Henry, L. A., \& Hill, E. (2016). Experiences of autism diagnosis: A survey of over 1000 parents in the United Kingdom. Autism, 20, 153-162. https://doi.org/10. $1177 / 1362361315573636$

de Meyrick, J. (2003). The Delphi method and health research. Health Education, 103, 7-16. https://doi.org/10.1108/096542803104591 12

Duckett, S. (2020). What should primary care look like after the COVID-19 pandemic? Australian Journal of Primary Health, 26, 207-211. https://doi.org/10.1071/PY20095

Fallowfield, L., \& Jenkins, V. (2004). Communicating sad, bad, and difficult news in medicine. The Lancet, 363, 312-319. https://doi. org/10.1016/S0140-6736(03)15392-5

Filipek, P. A., Accardo, P. J., Ashwal, S., Baranek, G. T., Cook, E. H., Dawson, G., Gordon, B., Gravel, J. S., Johnson, C. P., Kallen, R. J., Levy, S. E., Minshew, N. J., Ozonoff, S., Prizant, B. M., Rapin, I., Rogers, S. J., Stone, W. L., Teplin, S. W., Tuchman, R. F., \& Volkmar, F. R. (2000). Practice parameter: Screening and diagnosis of autism. Neurology, 55, 468-479.

Harrison, M. E., \& Walling, A. (2010). What do we know about giving bad news? A review. Clinical Pediatrics, 49, 619-626. https://doi. org/10.1177/0009922810361380

Hasnat, M., \& Graves, P. (2000). Disclosure of developmental disability: A study of parent satisfaction and the determinants of satisfaction. Journal of Paediatrics and Child Health, 36, 32-35. https://doi.org/10.1046/j.1440-1754.2000.00463.x
Haute Autorité de Santé. (2018). Autism spectrum disorder-Warning signs, detection, diagnosis and assessment in children and adolescents. Saint-Denis La Plaine.

Hayes, J., Ford, T., Rafeeque, H., \& Russell, G. (2018). Clinical practice guidelines for diagnosis of autism spectrum disorder in adults and children in the UK: A narrative review. BMC Psychiatry. https://doi.org/10.1186/s12888-018-1800-1

Hennel, S., et al. (2016). Diagnosing autism: Contemporaneous surveys of parent needs and paediatric practice. Journal of Paediatrics and Child Health, 52, 506-511. https://doi.org/10.1111/jpc.13157

Hohmann, E., Cote, M. P., \& Brand, J. C. (2018). Research pearls: Expert consensus based evidence using the Delphi method. Arthroscopy, 34, 3278-3282. https://doi.org/10.1016/j.arthro. 2018.10.004

Johnson, C. P., \& Myers, S. M. (2007). Identification and evaluation of children with autism spectrum disorders. Pediatrics, 120, 1183. https://doi.org/10.1542/peds.2007-2361

Jorm, A. F. (2015). Using the Delphi expert consensus method in mental health research. Australian and New Zealand Journal of Psychiatry, 49, 887-897. https://doi.org/10.1177/0004867415600891

Kanne, S. M., Gerber, A. J., Quirmbach, L. M., Sparrow, S. S., Cicchetti, D. V., \& Saulnier, C. A. (2011). The role of adaptive behavior in autism spectrum disorders: Implications for functional outcome. Journal of Autism and Developmental Disorders, 41, 1007-1018. https://doi.org/10.1007/s10803-010-1126-4

Klopper, F. K. (2017). High-functioning autism spectrum disorder: phenotypic subgroups, diagnostic instruments, and predictors of behavioural and emotional functioning.

Kraper, C. K., Kenworthy, L., Popal, H., Martin, A., \& Wallace, G. L. (2017). The gap between adaptive behavior and intelligence in autism persists into young adulthood and is linked to psychiatric co-morbidities. Journal of Autism and Developmental Disorders, 47, 3007-3017. https://doi.org/10.1007/s10803-017-3213-2

Lecouturier, J., et al. (2008). Appropriate disclosure of a diagnosis of dementia: Identifying the key behaviours of "best practice." BMC Health Services Research, 8, 95-95. https://doi.org/10.1186/ 1472-6963-8-95

Levac, D., Colquhoun, H., \& O'Brien, K. K. (2010). Scoping studies: Advancing the methodology. Implementation Science: IS, 5, 69. https://doi.org/10.1186/1748-5908-5-69

Liddicoat, P. (2018). Breaking bad news. InnovAiT, 11, 671-675. https://doi.org/10.1177/1755738018797963

Ministries of Health and Eduction. (2016). New Zealand autism spectrum disorders guideline. Ministry of Health.

Mulligan, J., Macculloch, R., Good, B., \& Nicholas, D. B. (2012). Transparency, hope, and empowerment: A model for partnering with parents of a child with autism spectrum disorder at diagnosis and beyond. Social Work in Mental Health, 10, 311-330. https:// doi.org/10.1080/15332985.2012.664487

Munn, Z., Peters, M. D. J., Stern, C., Tufanaru, C., McArthur, A., \& Aromataris, E. (2018). Systematic review or scoping review? Guidance for authors when choosing between a systematic or scoping review approach. BMC Medical Research Methodology, 18, 143-143. https://doi.org/10.1186/s12874-018-0611-x

National Initiative for Autism: Screening and Assessment. (2003). National autism plan for children. The National Autistic Society.

National Institute for Health Care and Excellence. (2017). Autism spectrum disorder in under 19s: Recognition, referral and diagnoisis-Clinical guideline [128].

New York State Department of Health, Bureau of Early Intervention (2017). New York State Department of Health clinical practice guideline on assessment and intervention services for young children (Age 0-3) with autism spectrum disorders.

Nissenbaum, M. S., Tollefson, N., \& Reese, R. M. (2002). The interpretative conference: Sharing a diagnosis of autism with families. 
Focus on Autism and Other Developmental Disabilities, 17, 30-43. https://doi.org/10.1177/108835760201700103

Pelco, L. E., Ward, S. B., Coleman, L., \& Young, J. (2009). Teacher ratings of three psychological report styles. Training and Education in Professional Psychology, 3, 19-27. https://doi.org/10.1037/ 1931-3918.3.1.19

Penner, M., Anagnostou, E., Andoni, L. Y., \& Ungar, W. J. (2018). Systematic review of clinical guidance documents for autism spectrum disorder diagnostic assessment in select regions. Autism, $22,517-527$

Peters, M., Godfrey, C., McInerney, P., Munn, Z., Tricco, A. C., \& Khalil, H. (2020). Chapter 11: Scoping reviews (2020 version). In E. Aromataris \& Z. Munn (Eds.), JBI Manual for evidence synthesis.JBI.

Potter, C. A. (2017). "I received a leaflet and that is all": Father experiences of a diagnosis of autism. British Journal of Learning Disabilities, 45, 95-105. https://doi.org/10.1111/bld.12179

Rogers, C. L., Goddard, L., Hill, E. L., Henry, L. A., \& Crane, L. (2016). Experiences of diagnosing autism spectrum disorder: A survey of professionals in the United Kingdom. Autism, 20, 820-831. https://doi.org/10.1177/1362361315611109

Ruiz Calzada, L., Pistrang, N., \& Mandy, W. (2012). High-functioning autism and asperger's disorder: Utility and meaning for families. Journal of Autism and Developmental Disorders, 42, 230-243. https://doi.org/10.1007/s10803-011-1238-5

Scottish Intercollegiate Guidelines Network (SIGN). (2016). Assessment, diagnosis and interventions for autism spectrum disorders SIGN Publication no 145. SIGN.

Sekercioglu, N., et al. (2017). A critical appraisal of chronic kidney disease mineral and bone disorders clinical practice guidelines using the AGREE II instrument. International Urology and Nephrology, 49, 273-284. https://doi.org/10.1007/s11255-016-1436-3

Sheets, K. B., Best, R. G., Brasington, C. K., \& Will, M. C. (2011). Balanced information about Down syndrome: What is essential? American Journal of Medical Genetics, 155, 1246-1257. https:// doi.org/10.1002/ajmg.a.34018

Siering, U., Eikermann, M., Hausner, E., Hoffmann-Esser, W., \& Neugebauer, E. (2013). Appraisal tools for clinical practice guidelines: A systematic review. PLoS ONE. https://doi.org/10.1371/journal. pone. 0082915

Simonoff, E., Pickles, A., Charman, T., Chandler, S., Loucas, T., \& Baird, G. (2008). Psychiatric disorders in children with autism spectrum disorders: Prevalence, comorbidity, and associated factors in a population-derived sample. Journal of the American Academy of Child \& Adolescent Psychiatry, 47, 921-929. https:// doi.org/10.1097/CHI.0b013e318179964f

Taylor, J., \& Warren, Z. (2012). Maternal depressive symptoms following autism spectrum diagnosis. Journal of Autism and
Developmental Disorders, 42, 1411-1418. https://doi.org/10. 1007/s10803-011-1375-x

Thompson Founation for Autism and the Division of Developmental Disabilities (2010). Autism spectrum disorders: Missouri best practice guidelines for screening, diagnosis, and assessment. Missouri Department of Mental Health.

Tricco, A. C., et al. (2018). PRISMA extension for scoping reviews (PRISMA-ScR): Checklist and explanation. Annals of Internal Medicine, 169, 467. https://doi.org/10.7326/M18-0850

University of Connecticut School of Medicine and Dentistry. (2013). Connecticut guidelines for a clinical diagnosis of autism spectrum disorder Articles-Patient Care. vol 45.

Ure, A., Rose, V., Bernie, C., \& Williams, K. (2018). Autism: One or many spectrums? Journal of Paediatrics and Child Health, 54, 1068-1072. https://doi.org/10.1111/jpc.14176

Veritas Health Innovation. (2015). Covidence systematic review software. In. www.covidence.org.

Volkmar, F., Siegel, M., Woodbury-Smith, M., King, B., McCracken, J., \& State, M. (2014). Practice parameter for the assessment and treatment of children and adolescents with autism spectrum disorder. Journal of the American Academy of Child \& Adolescent Psychiatry, 53, 237-257. https://doi.org/10.1016/j.jaac.2013.10.013

Ward, S. L., Sullivan, K. A., \& Gilmore, L. (2016). Practitioner perceptions of the assessment and diagnosis of autism in Australia. Australian Psychologist, 51, 272-279. https://doi.org/10.1111/ap. 12211

Whitehouse, A., Evans, K., Eapen, V., \& Wray, A. (2018). A national guideline for the assessment and diagnosis of autism spectrum disorders in Australia. Cooperative Research Centre for Living with Autism.

Williams, K., Woolfenden, S., Roberts, J., Rodger, S., Bartak, L., \& Prior, M. (2014). Autism in context 2: Assessment, intervention and services in Australia. Journal of Paediatrics and Child Health, 50, 341-346

World Health Organization. (2007). The international classification of functioning, disability and health, children and youth. WHO.

World Health Organization. (2018). International classification of diseases for mortality and morbidity statistics $\left(11^{\text {th }}\right.$ Revision $)$

Wosik, J., et al. (2020). Telehealth transformation: COVID-19 and the rise of virtual care. Journal of the American Medical Informatics Association, 27, 957-962. https://doi.org/10.1093/jamia/ocaa067

Yan, J., Min, J., \& Zhou, B. (2013). Diagnosis of pheochromocytoma: A clinical practice guideline appraisal using AGREE II instrument. Journal of Evaluation in Clinical Practice, 19, 626-632. https://doi.org/10.1111/j.1365-2753.2012.01873.x

Publisher's Note Springer Nature remains neutral with regard to jurisdictional claims in published maps and institutional affiliations. 